\title{
PRÁTICA DA EPISIOTOMIA NO PARTO: DESAFIOS PARA A ENFERMAGEM
}

\section{PRACTICE OF EPISIOTOMY DURING CHILDBIRTH: CHALLENGES FOR NURSING}

\section{PRÁCTICA DE LA EPISIOTOMÍA DURANTE EL PARTO: DESAFIOS PARA LA ENFERMERÍA}

Kelen da Costa Pompeu ${ }^{1}$, Juliane Scarton ${ }^{2}$, Luiza Cremonese ${ }^{3}$, Rosiele Gomes Flores ${ }^{2}$, Maria Celeste Landerdahl ${ }^{4}$, Lúcia Beatriz Ressel ${ }^{5}$.

\section{RESUMO}

Objetivo: identificar o conhecimento de puérperas sobre a episiotomia e como se deu a realização dessa prática no parto. Método: trata-se de uma pesquisa do tipo descritiva, com abordagem qualitativa, realizada em um hospital no Rio Grande do Sul. As informantes foram oito puérperas que vivenciaram o parto vaginal com episiotomia. Na coleta de dados, utilizou-se a técnica de entrevista semiestruturada com posterior análise temática. Resultados: apontam para a falta de esclarecimento e o desconhecimento das participantes quanto ao termo episiotomia, fatores que podem influenciar o evento do parto e, ainda, a violência de gênero que ocorre nas instituições de saúde, como a violência obstétrica, a qual está perpetrada nas maternidades e, muitas vezes, não é percebida por quem as pratica e, também, por quem sofre essa violência. Conclusão: Foi possível perceber que as participantes possuem poucas informações sobre a episiotomia e notou-se que o desconhecimento das mulheres sobre essa prática é fator que contribui para a realização rotineira desse procedimento.

Descritores: Episiotomia; Enfermagem; Parto; Parto humanizado.

\section{ABSTRACT}

Objective: identify the knowledge of recent mothers about episiotomy and as the realization of this practice in childbirth. Method: It is a descriptive research with qualitative approach, carried out in a hospital in Rio Grande do Sul. The informants were eight recent mothers who have experienced the vaginal delivery with episiotomy. In data collection, it was used the semi-structured interview technique, with further analysis. Results point to a lack of clarification and the ignorance of the participants as the term episiotomy, factors that can influence the event of childbirth and the gender violence that occurs in health institutions, such as obstetric violence which is perpetrated in maternity wards and, often, is not perceived by those who practice and also for those who suffer this violence. Conclusion: It was possible to notice that the participants have little information about the episiotomy and noticed that the ignorance of women on this practice is contributing factor to carry out routine this procedure.

Descriptors: Episiotomy; Nursing; Parturition; Humanizing delivery.

\section{RESUMEN}

Objetivo: identificar el conocimiento de las madres recientes como la realización de esta práctica en el parto y episiotomía. Método: Es una investigación descriptiva con enfoque cualitativo, llevó a cabo en un hospital de Rio Grande do Sul. Los informantes fueron ocho madres recientes que han experimentado el parto vaginal con episiotomía. Recopilación de datos, se utilizó la técnica de entrevista semiestructurada, con análisis posterior. Resultados: apuntan a una falta de clarificación y la ignorancia de los participantes como la episiotomía de término, factores que pueden influir en el evento del parto y la violencia de género que ocurre en las instituciones de salud, como la violencia obstétrica que es perpetrado en salas de maternidad y, a menudo, no es percibida por quienes la practican y también para aquellos que sufren esta violencia. Conclusión: Fue posible notar que los participantes tienen poca información sobre la episiotomía y notó que la ignorancia de las mujeres en esta práctica está contribuyendo factor para llevar a cabo la rutina de este procedimiento.

Descriptores: Episiotomía; Enfermería; Parto; Parto humanizado.

\footnotetext{
${ }^{1}$ Graduada em Enfermagem pela Universidade Federal de Santa Maria (UFSM). ${ }^{2}$ Graduada em Enfermagem. Mestre em Enfermagem pela Universidade Federal de Santa Maria. Santa Maria (RS), Brasil. ${ }^{3}$ Graduada em Enfermagem. Mestranda em Enfermagem do Programa de Pós-Graduação em Enfermagem/PPGEnf pela Universidade Federal de Santa Maria/UFSM. Santa Maria (RS), Brasil. ${ }^{4}$ Graduada em Enfermagem. Doutoranda em Enfermagem. Professora do Curso de Graduação em Enfermagem pela Universidade Federal de Santa Maria/UFSM. ${ }^{5}$ Graduada em Enfermagem. Doutora em Enfermagem. Professora associada ao Departamento de Enfermagem da Universidade Federal de Santa Maria/UFSM. Santa Maria (RS), Brasil.
}

Como citar este artigo:

Pompeu KC, Scarton J, Cremonese L, et al. Prática da episiotomia no parto: Desafios para a enfermagem. Revista de Enfermagem do Centro-Oeste Mineiro. 2017;7:e1142. [Access__]; Available_ in:___.__oi: http://dx.doi.org/10.19175/recom.v7i0.1142 


\section{INTRODUÇÃO}

O parto constitui um dos principais acontecimentos na vida da mulher, pois é o evento que resulta no nascimento de uma nova vida. É uma experiência que perpassa aspectos psicológicos, emocionais e sociais, sendo vivida de acordo com a cultura em que cada mulher está inserida. A forma de parir é igualmente influenciada por essa cultura e vem sendo modificada ao longo da história ${ }^{(1)}$.

No passado, era comum o parto domiciliar atendido por parteiras leigas, também conhecidas por comadres. Estas eram chamadas pelas parturientes e detinham conhecimento empírico dos períodos gravídico, parturitivo e puerperal. 0 parto era um evento partilhado por mulheres, no qual o homem não participava, além disso, o processo fisiológico do parto era sempre que possível respeitado ${ }^{(2)}$.

A entrada da figura masculina no ato de parir ocorreu a partir do século XVIII, quando a medicina começou a interessar-se pela reprodução, incorporando a prática obstétrica cirúrgica ao parto. Em razão desse fato, as taxas de mortalidade das mães e crianças aumentaram, principalmente pela febre puerperal, pela instrumentalização do parto e pela cesárea. 0 parto que, até então, era um evento fisiológico, tornou-se patológico, sendo necessária a hospitalização da mulher para seu manejo ${ }^{(3)}$.

A partir dessa institucionalização, as intervenções tornaram-se mais comuns. Entre estas, pode-se citar a restrição no leito, o uso de ocitocina sintética, toques repetidos por mais de um profissional, amniotomia de rotina, manobra de kristeller, lavagem intestinal, uso de fórceps, episiotomia, dentre outras. Neste estudo será destacada a prática da episiotomia por ser uma das intervenções mais utilizadas na prática obstétrica e por fazer parte das inquietações da autora desta pesquisa ${ }^{(4)}$.

Ao longo dos anos, a episiotomia vem sendo largamente praticada no Brasil. Pesquisa nacional de demografia da saúde da criança e da mulher revelou um índice de $71,6 \%$ de episiotomia no Brasil e um índice de $78,5 \%$ no estado do Rio Grande do Sul ${ }^{(5)}$. Esses números superam, e muito, a porcentagem recomendada pela Organização Mundial de Saúde (OMS) que sugere uma taxa ideal de episiotomia nos diversos serviços em torno de $10 \%$, realidade em muitos países europeus ${ }^{(6)}$.

Os dados revelam ${ }^{(5)}$ que essa prática vai ao desencontro do que preconiza a Política de
Humanização no Pré-Natal e Nascimento (PHPN). Esta visa à adoção de medidas e procedimentos sabidamente benéficos para o acompanhamento do parto e nascimento, evitando práticas intervencionistas desnecessárias que, embora tradicionalmente realizadas, não beneficiam a mulher, nem o recém-nascido, e que, com frequência, acarretam maiores riscos para $\operatorname{ambos}^{(7)}$.

Na literatura, não há a recomendação de abolir a episiotomia de uma forma geral, mas de restringi-la às pacientes com relação ao custobenefício evidente. Em relação a isso, a Organização Mundial de Saúde (OMS) aconselha a realização da episiotomia em situações como sofrimento fetal, progresso insuficiente do parto e lesão iminente de $3^{\circ}$ grau do períneo ${ }^{(6)}$. Contudo, não existe um consenso na literatura sobre quais seriam essas situações, somente que seu uso deveria se restringir a situações clínicas específicas, de acordo com a determinação do serviço ${ }^{(8)}$.

No Brasil, quase a totalidade dos partos vaginais é precedida pela episiotomia. Sabe-se que esse procedimento pode ser reduzido e até mesmo evitado com o auxílio de exercícios para o fortalecimento do períneo, como a massagem perineal a partir das 34 semanas de gestação ${ }^{(9)}$. Também, a adoção de uma posição não horizontalizada contribui significativamente para que não haja laceração ${ }^{(4)}$.

A enfermagem tem papel fundamental para modificar o panorama atual da assistência ao parto, ao atuar para reformular o uso de práticas indevidas, como a episiotomia ${ }^{(10)}$. Quanto a isso, as políticas públicas de saúde reforçam o caráter legal para a implementação de práticas benéficas no parto, como a criação da PHPN, e também o conjunto de recomendações de boas práticas na assistência ao parto e nascimento, elaborado pela $\mathrm{OMS}^{(6)}$.

Cabe ressaltar que a Lei do Exercício Profissional 7.498/86 e o Decreto-Lei $94.406 / 87$ asseguram ao enfermeiro obstetra realizar assistência à parturiente e ao parto eutócico, destacando a responsabilidade na articulação de um cuidado humanizado para a redução de intervenções desnecessárias ${ }^{(11)}$. Acredita-se que o enfermeiro, com base no conhecimento científico, traz consigo a capacidade de possibilitar o empoderamento às mulheres $e$, por meio deste, se darão as modificações nos paradigmas atuais.

Este estudo justifica-se por estar alinhado às propostas da Agenda Nacional de Prioridades 
de Pesquisa em Saúde, do Ministério da Saúde ${ }^{(12)}$, pela premissa de que a redução de intervenções desnecessárias no parto é fator primordial para o alcance da humanização da assistência ao parto e nascimento. Ainda, devido aos riscos e complicações ocasionadas na realização de tal procedimento, como a predisposição à mulher ao aumento da perda sanguínea, infecção, disfunção sexual, dispareunia, incontinência urinária, prolapso do colo do útero e também de consequências mais tardias dos efeitos físicos e psicológicos ${ }^{(13)}$.

Assim, com base no exposto, estabeleceuse a seguinte questão de pesquisa: $O$ que as puérperas sabem sobre a episiotomia e como se deu a realização de tal prática no parto? E como objetivo: identificar o conhecimento de puérperas sobre a episiotomia e como se deu a realização dessa prática no parto.

\section{MÉTODO}

Estudo de campo de abordagem qualitativa, do tipo descritivo, desenvolvido na unidade tocoginecológica de um hospital de caráter federal, ligado ao Sistema Único de Saúde (SUS), localizado no estado do Rio Grande do Sul. As participantes foram mulheres puérperas que vivenciaram o parto vaginal com episiotomia.

Os critérios de inclusão compreenderam mulheres submetidas ao parto vaginal com episiotomia, internadas no cenário de estudo no período de coleta de dados; que resultassem em recém-nascidos vivos; maiores de 18 anos. As participantes enquadradas nos critérios de inclusão foram informadas, individualmente, acerca dos objetivos, possíveis riscos e benefícios da pesquisa, assim como a apresentação do Termo de Consentimento Livre e Esclarecido (TCLE).

A coleta dos dados foi realizada por meio de entrevista semiestruturada, no período de abril e maio de 2014. Para a abordagem das participantes, foi respeitado o período de 24 horas após o parto. O local para realização das entrevistas foi a sala de reuniões da unidade. No momento da entrevista, o recém-nascido ficou aos cuidados do(a) acompanhante da participante do estudo. As entrevistas foram gravadas com o auxílio de um gravador digital e, posteriormente, foram transcritas na íntegra visando possibilitar a análise e interpretação fidedignas dos resultados. O término da coleta de dados ocorreu quando respondido o objetivo da pesquisa e pela saturação dos dados ${ }^{(14)}$.
Para a análise dos dados, foi utilizada a Análise de Conteúdo temática, proposta por Minayo ${ }^{(14)}$, que se caracteriza por dois momentos operacionais. O primeiro momento foi de inclusão das determinações fundamentais do estudo, o qual foi mapeado na fase exploratória da investigação. Nesta fase, buscou-se o contexto histórico-social do grupo a ser estudado, tomando-se como centro de análise a prática social e a ação humana.

O segundo momento, a fase interpretativa, constituiu-se de duas etapas: a ordenação dos dados por meio da transcrição do material obtido através da coleta dos dados, leituras do material e organização dos relatos, os quais determinaram o início da classificação dos resultados obtidos; a classificação dos dados em que se realizou a leitura horizontal e exaustiva dos achados, e através de leituras flutuantes foi possível apreender as estruturas de relevância e as ideias centrais dos depoimentos; a leitura transversal foi o momento de estabelecer relações entre os dados, construindo as categorias ou unidades de sentido. A análise final compreendeu a fase na qual os dados obtidos foram confrontados com a literatura acerca do tema.

As participantes do estudo constituíram-se de oito puérperas cujas idades situavam-se entre 18 e 24 anos. Quanto à situação de paridade, todas eram primíparas. Em relação ao estado civil, uma era casada, uma encontrava-se em união estável e seis eram solteiras. No que tange ao grau de escolaridade, uma cursava nível superior, quatro concluíram ensino médio e três apresentavam o ensino fundamental incompleto. Quanto à situação laboral, quatro eram donas de casa, uma vendedora, uma consultora de vendas, uma atendente e uma auxiliar de cozinha.

Para preservar a identidade das participantes, as mesmas foram identificadas pelas letras $\mathrm{PI}$, seguidas do numeral referente à realização das entrevistas (PI1, PI2, PI3...). As letras referem-se à campanha "Períneo Íntegro", incorporada pelo movimento de Humanização do Parto, que intenta acabar com as episiotomias de rotina. Foram seguidos os princípios éticos da Resolução 466/2012, que regulamentam as pesquisas com seres humanos ${ }^{(15)}$. O projeto foi aprovado sob Certificado de Apresentação para Apreciação Ética (CAAE) 27353814.5.0000.5346.

\section{RESULTADOS E DISCUSSÃO}

Após a análise dos dados obtidos no estudo e para melhor discussão dos achados, 
formularam-se as seguintes categorias: Conhecimento das puérperas acerca da episiotomia no parto: o cortezinho lá embaixo; e Realização da episiotomia na voz de puérperas.

\section{Conhecimento das puérperas acerca da episiotomia no parto: o cortezinho lá embaixo}

Os profissionais de saúde, em especial a enfermagem, devem prestar um cuidado centrado nas necessidades individuais de cada mulher. Estes devem fornecer orientações, esclarecer dúvidas, bem como acolher, aconselhar sobre as práticas cabíveis em cada caso e auxiliar no processo parturitivo ${ }^{(4)}$. A qualidade da assistência, bem como a escuta ativa, vínculo, responsabilização, resolubilidade e acesso à continuidade do cuidado são ações que permeiam um cuidado à mulher de forma plena. Logo, é preciso garantir acesso à informação correta e em linguagem adequada, garantindo qualidade de assistência à mulher no pré-natal, parto e puerpério ${ }^{(16)}$.

Nesse contexto, considera-se de extrema importância que os profissionais de saúde tenham ciência sobre o grau de informação que as pacientes têm sobre os procedimentos realizados e a importância de fornecer informações corretas e em linguagem adequada. Desse modo, percebe-se nas falas a seguir o desconhecimento das participantes quanto ao termo episiotomia: "[...] episiotomia? Nunca ouvi falar[...]" (PI 1). "[...] eu não faço a mínima ideia do que seja isso [...]" (PI 2). "[...] não sei o que é essa palavra [...]" (PI 6)".

O termo técnico "episiotomia" tão frequentemente usado pelos profissionais de saúde não faz parte do cotidiano dessas mulheres. Também, como se percebe no relato a seguir, em nenhum momento foi explicado a estas sobre o significado de tal termo em linguagem clara. "[...] na verdade esse nome é novo, eu nem sabia como se chamava, fiquei sabendo agora, hoje, quando o médico veio perguntar se tinham feito e eu respondi que não, que nem sabia o que tinham feito, por nome eu não sabia. Agora que eu sei que é o cortezinho que eles fazem na hora do parto [...]" (PI 8).

$O$ relato expõe que a participante desconhecia o termo episiotomia quando se refere a esta como um "cortezinho", compreendendo-o assim como um procedimento necessário para o nascimento de seu filho. Cabe destacar que as informações e orientações sobre o processo parturitivo e as terminologias usuais no meio profissional como a episiotomia, bem como as indicações para realização ou não, deveriam acontecer antes mesmo da mulher dar entrada nas instituições hospitalares.

Uma vez que a assistência e o empoderamento da mulher iniciam-se no prénatal com ações educativas e escuta qualificada com o objetivo de acrescer subsídios sobre o ciclo gravídico-puerperal e valorizar as experiências de vida das usuárias e o seu próprio conhecimento sobre o corpo para a busca de autonomia. Sendo assim, compete aos profissionais de saúde a reflexão acerca da assistência pré-natal e a busca de elementos que subsidiem o planejamento, a implementação e avaliação de seus cuidados a fim de atingir um patamar de qualidade ${ }^{(17)}$.

Logo, o diálogo respeitoso entre os profissionais de saúde e a mulher é o primeiro passo para uma assistência humanizada ${ }^{(17)}$. Assim, a humanização da assistência pode ser entendida como uma possibilidade de cuidar, atendendo às necessidades humanas do usuário. Para isso, é necessário respeitá-las, considerar seus sentimentos e individualidade a fim de permitirIhe o protagonismo de sua própria história.

Contudo, este estudo mostra que, contrariamente ao que se preconiza, o diálogo nem sempre acontece e as usuárias ainda necessitam de esclarecimentos, tendo em vista que, após elucidação realizada pela entrevistadora sobre o significado da palavra episiotomia, imediatamente as mesmas demonstraram compreender o termo: "[...] 0 cortezinho? Recebi [...]" (PI 4). "[...] Já, mas não por esse nome [...]" (PI 7). "[...] Ah, sim! Esse sim [...] (PI 5).

Evidencia-se, nos fragmentos, a episiotomia como um "cortezinho", minimizada por meio das palavras diminutas. Sendo assim, considera-se que essas mulheres têm pouco ou nenhum conhecimento do que representa o procedimento, uma vez que compreende um corte na vulva, isto é, uma incisão cirúrgica que pode acarretar em danos físicos e psicológicos.

Destaca-se, também, que esse modo de pensar pode estar associado ao contexto cultural em que vivem essas mulheres, pois muitos fatores podem influenciar a sua percepção perante essa fase de sua vida, e aos acontecimentos que permeiam o evento do parto, conforme é possível ver nas falas: "[...] A minha tia já tinha me falado que, geralmente, na primeira gestação, no primeiro filho, eles fazem para facilitar a passagem do bebê [...]" (PI 5). "[...] 
É que, como eu tenho a minha mãe, que tem nove filhos e todos ela ganhou de parto normal, ela falou que eles davam um piquezinho lá para ajudar, para o nenê poder sair, caso a gente não completasse os dez dedos de dilatação, aí eles davam o piquezinho [...]" (PI 3).

Fica evidente, por meio das falas, o desconhecimento das mulheres acerca do próprio corpo e do processo fisiológico do parto, visto que compreendem a prática da episiotomia como um corte facilitador para a passagem do bebê e relacionado à evolução da dilatação uterina. Percebe-se, também, que a cultura familiar, em que os conhecimentos são repassados por meio de conversa informal, influencia na compreensão das mulheres e as faz acreditar que a episiotomia é necessária para boa evolução do parto.

Portanto, os saberes de cada mulher derivam do seu contexto familiar. Nestes espaços, comumente o corpo é visto como defeituoso e a vagina como inadequada para o processo fisiológico do nascimento, colaborando no imaginário popular de que a intervenção do obstetra é imprescindível. Assim, perpetua-se a manutenção da hegemonia médica, a qual é fortalecida pelo deficit de conhecimento das mulheres com relação à episiotomia rotineira ${ }^{(18)}$.

Segundo estudo, o homem resulta do meio cultural em que conviveu, refletindo-o no seu modo de viver, no seu conhecimento, bem como na experiência apanhada pelas gerações que o precederam $^{(19)}$. A cultura intervém nas necessidades básicas das pessoas e também na saúde, na doença, na vida e na morte. Essas mulheres fazem parte desse contexto e expõem em suas falas informações relacionadas ao processo parturitivo, que foram repassadas por familiares e que compõem o seu imaginário e a sua carga cultural.

Sendo assim, faz-se necessário o reconhecimento dos diversos valores, crenças, necessidades e expectativas relacionadas ao processo gravídico-puerperal para a construção de um cuidado individualizado. Além disso, o fornecimento de orientações sobre as práticas realizadas é imprescindível para que a mulher possa participar ativamente e sentir que tem o poder de colaborar para o seu bem-estar e do bebê $\hat{e}^{(16)}$.

Ademais, embora as questões culturais influenciem na compreensão das mulheres em relação aos acontecimentos do parto, os profissionais de saúde devem orientá-las, esclarecer suas dúvidas e realizar os cuidados que sejam compreendidos e consentidos por estas. $\mathrm{O}$ profissional deve esclarecer a mulher sobre as reais indicações de cada procedimento, de modo que ela possa participar na tomada de decisões que envolvem o seu corpo. Nesse sentido, seguem as crenças das participantes em relação às indicações para realização da episiotomia: "[...] Eu acredito que é para ter um espaço maior, porque o útero da gente dilata, né? E ali fora não tem essa dilatação, então, eu acredito que seja por isso, para ter esse espaço maior para o bebê passar [...]" (PI 1). "[...] Eu acho que pelo tamanho do bebê também [...]" (PI 2).

Nesse contexto, compreendem que o procedimento é realizado devido ao tamanho do bebê. Essa perspectiva trazida nos relatos evidencia uma percepção do corpo da mulher como sendo defeituoso. Além disso, destaca-se que a legítima necessidade de realização e o motivo pelo qual foi feito a episiotomia não foi esclarecido, tornando-se, portanto, desconhecido por elas.

Percebe-se, também, a vulnerabilidade da futura mãe, visto que a obstetrícia conceitua a episiotomia como uma intervenção imprescindível e favorável, mesmo com tantas evidências científicas disponíveis que vão contra a sua realização ${ }^{(20)}$. Esse modo de assistência tecnicista está arraigado na cultura de profissionais mecanicistas, que tiveram sua formação em modelos biomédicos e os perpetuam no ensino aos que chegam à prática hospitalar.

As mulheres aceitam a episiotomia porque acreditam na sua necessidade, creem que esse procedimento as protege e também ao seu bebê. Acreditam, também, que sua realização acelera o nascimento. Nessa direção, a falta de informação, muitas vezes, é geradora de insegurança, desamparo e, até mesmo, desencadeadora de atitudes agressivas, pois se revoltam diante dos profissionais que as deixam a mercê dos acontecimentos do seu parto ${ }^{(20)}$.

Percebeu-se nos relatos que há um reconhecimento, por parte de algumas participantes, quanto a práticas desnecessárias ainda realizadas rotineiramente no parto, porém não há movimento ativo delas para se opor a essa prática: "[...] Só que como ele [o bebê] é pequenininho, não teria necessidade disso [...]" (PI 2). "[...] eu li na internet que hoje em dia é errado o pique, que não pode mais também ninguém vir para cima da tua barriga e empurrar, que é tudo contra hoje em dia [...]" (P I4). 
Com base no exposto, embora a mulher tenha buscado informações e esteja ciente das recomendações, no momento do parto, submetese ao procedimento sem questionamentos, demostrando a percepção de que o profissional detém o conhecimento e que, portanto, não pode impor-se perante o mesmo. Nessa perspectiva, entende-se que as mulheres podem vivenciar o parto na sua plenitude, mas para isso é necessário estimular o conhecimento acerca do próprio corpo, práticas seguras no parto vaginal, riscos e complicações, bem como sobre a necessidade em alguns casos da realização de intervenções, entretanto é fundamental o empoderamento por meio do conhecimento.

\section{Realização da episiotomia na voz de puérperas.}

Os resultados apontam que a prática da episiotomia, muitas vezes, é realizada de forma rotineira sem o consentimento e conhecimento das mulheres. Estudo aponta ${ }^{(21)}$ que a mulher deve ser informada sobre a prática da episiotomia antes da sua realização, caso se faça necessária. Logo, ela deve ser orientada sobre os possíveis riscos e benefícios e deve autorizar ou não a realização desse procedimento.

Entretanto, neste estudo, a condução para realização da episiotomia não seguiu tal forma: "[...] Não, só me falaram depois. Ela disse: "Agora tu fica aqui que a gente vai costurar, vai fazer todo o procedimento". Aí eu fiquei lá, esperando [...]" (PI 2). "[...] Ela foi com a tesoura e fez. Mas uma vez eu li na internet que isso hoje em dia é errado, fazer este corte. Mas eu não fiquei sabendo nada na hora, ela chegou e fez. Ela tinha feito o corte e que tinha que dar os pontos [...]" (PI 4). "[...] A doutora só falou que ia ter que dar um piquezinho, daí eu fiquei tranquila, falei que não tinha problema [...]" (PI 3).

Nessa esteira de pensamento, as mulheres foram unânimes ao negar que lhes pediram autorização para realização da episiotomia e apenas foram informadas após o ato, isto é, no momento da sutura ou na hora em que a episiotomia estava sendo realizada. Além disso, percebe-se que elas ficaram inertes, indiferentes com os procedimentos e subordinadas ao saber médico, o que pode ser descrito como a autopercepção passiva, diferentemente das mulheres questionadoras, que recusam e reajustam seu modo de viver na sociedade ${ }^{(20)}$.

Cotidianamente, as mulheres são submetidas a práticas obstétricas rotineiras e intervencionistas, muitas vezes desnecessárias, sem serem informadas. Nesse sentido, existem controvérsias em relação ao código de ética médica que determina que seja vedado deixar de obter o consentimento da paciente ou responsável sem esclarecer sobre o que será realizado, salvo em casos de risco iminente de morte ${ }^{(22)}$.

A prática rotineira da episiotomia não é respaldada pelo código de ética médica, assim como, sua realização sem o consentimento da parturiente. No entanto, continua sendo implementada nas maternidades, mesmo sendo considerada uma forma de mutilação genital, representando o poder da obstetrícia sobre o corpo da mulher, negando seu poder de decisão(4).

Em relação ao exposto, o parto, inúmeras vezes, ainda é conduzido como um evento patológico como se pode perceber no depoimento: "[...] Eu pensei que eu fosse chegar lá e ter o bebê, só que veio o anestesia, veio o corte, veio os pontos. Tudo isso foi de surpresa. Quando me levaram para a sala de parto, eu pensei que era para fazer a força e o nenê sairia, aí eu fiquei fazendo força e não adiantava, então vieram com a agulha, com a anestesia que eu nem imaginava que iria ter. Eu já estava apavorada, então veio uma [profissional] com uma tesoura na mão e não falou nada. Então uma [profissional] gritou lá no fundo: "Ai, estas tesouras, deixam só os cacos para cá, para a obstetrícia. A gente tenta cortar, tenta cortar, e não corta". Então eu fui me apavorando. Depois simplesmente pediram para eu ficar quieta, que iam "dar os pontos", e eu não sabia, e não sei até hoje, quantos são, onde são e como foram feitos [...]" (PI 2).

Vale observar que a participante referiu acreditar que não sofreria intervenções no seu parto e que seria apenas potencializar a força e o bebê nasceria de forma natural. No entanto, o modelo tecnocrático é nítido em suas palavras quando o profissional que assistiu seu parto sequer permitiu que a mesma participasse do processo ou pudesse decidir sobre seu corpo.

Os relatos evidenciam que o corpo da mulher é tido como objeto passivo de intervenções e que sua autonomia é desvalorizada, uma vez que a mesma apenas recebe ordens sem ao menos ser informada previamente. Sendo assim, entende-se que, com oportunas informações e orientações, é possível evitar vivências negativas nesse período, pois se 
pode tornar o momento do parto mais prazeroso e centrado na mulher enquanto protagonista desse evento.

O modelo atual de assistência ao parto e nascimento deve levar em consideração a prática de cuidado baseada em evidências científicas e reformular o modelo de assistência. Modelo esse em que ainda perdura a realização de práticas rotineiras, sem levar em consideração a individualidade de cada mulher como um ser digno de respeito, escuta, orientação, atenção.

Cabe mencionar como limitação do estudo o fato de informações adicionais não serem abordadas na pesquisa, como o conhecimento das puérperas acerca dos riscos e complicações tardias à realização da episiotomia, tais como hemorragia significativa, dor no pós-parto, edema, infecções, disfunção sexual, incontinência urinária e fecal, dentre outras. Sugere-se, assim, a realização de estudos que contemplem a associação dessas complicações com a prática da episiotomia no parto, tendo em vista que esses acontecimentos interferem de forma significativa na qualidade de vida atual e futura de tais mulheres.

\section{CONCLUSÃO}

As participantes possuem pouco conhecimento sobre a episiotomia, desconhecem o nome técnico-científico e reconhecem o procedimento como necessário e normal no processo de nascimento. Logo, o enfermeiro e demais profissionais de saúde envolvidos na atenção ao parto têm o dever de acolher a mulher e ofertar suporte por meio de orientações e esclarecimentos de eventuais dúvidas, tendo em vista que, em determinados casos, o uso da episiotomia pode vir a ser necessário, mas que o uso rotineiro de tal procedimento não possui evidências científicas.

Salienta-se a necessidade de transformação do cenário, em que o modelo biomédico, neste estudo, ainda se mostra como predominante. Mudança essa que pode se dar por meio da educação em saúde desde a atenção básica no pré-natal, assim como de reavaliar permanentemente $o$ conhecimento técnicocientífico de profissionais atuantes em centros de saúde a fim de viabilizar e substituir a realização da episitomia por métodos não farmacológicos no primeiro estágio do trabalho de parto.

Destaca-se, ainda, a necessidade de promover às mulheres e familiares o conhecimento para a tomada de decisão perante os eventos que permeiam o parto. Sugere-se novos estudos para avaliar as dificuldades dos profissionais de saúde para a implementação de práticas seguras no parto vaginal e na eliminação do uso rotineiro de práticas, muitas vezes desnecessárias, como a episiotomia.

\section{REFERÊNCIAS}

1. Oliveira ASS, Rodrigues DP, Guedes MVC. Percepção de puérperas acerca do cuidado de enfermagem durante o trabalho de parto e parto. Rev. enferm. UERJ, Rio de Janeiro. [Internet]. 2011 [acesso em: 21 aug 2016];19(2):24954.Disponível em: http://www.facenf.uerj.br/v19n2/v19n2a13.pdf 2. Seibert SL, Barbosa AJLS, Santos JM, Vargens OMC. O significado de desmedicalização da assistência ao parto no hospital: análise da concepção de enfermeiras obstétricas. Rev Esc Enferm USP. [Internet]. 2008 [acesso em: 21 aug 2016];42(2):339-46. Disponível em: http://www.scielo.br/pdf/reeusp/v42n2/a17.pdf 3. Dodou HD, Rodrigues DF, Guerreiro EM, Guedes MVC, Lago PN, Mesquita NS. A contribuição do acompanhante para a humanização do parto e nascimento: percepções de puérperas. Esc. Anna Nery Rev. Enferm. [Internet]. 2014 [acesso em: 10 nov 2014]; 18(2):262-9. Disponível em: http://www.scielo.br/scielo.php?script=sci arttex t\&pid=S1414-81452014000200262

4. Leal MC, Pereira APE, Domingues RMSM, Theme MM, Dias MAB, Pereira $M N$, et al. Intervenções obstétricas durante o trabalho de parto e parto em mulheres brasileiras de risco habitual. Cad. saúde pública. [Internet]. 2014 [acesso em: 15 set 2014]; 30(1):17-32. Disponível em: http://www.scielo.br/scielo.php?pid=S0102311X2014001300005\&script=sci arttext

5. Lago T, Lima LP. Assistência à gestação, ao parto e puerpério: diferenciais regionais e desigualdades socioeconômicas. In: BRASL. Ministério da Saúde. Pesquisa Nacional de Demografia da Saúde da Criança e da MulherPNDS 2006: dimensões no processo reprodutivo e da saúde da criança. Brasília, 2006:151-70.

6. Organização Mundial da Saúde. Saúde Materna e Neonatal. Unidade de Maternidade Segura Saúde Reprodutiva e da Família. Assistência ao parto normal: um guia prático de saúde materna e neonatal. Unidade de Maternidade Segura. Saúde Reprodutiva e da Família. Genebra: Organização Mundial da Saúde; 1996.

7. Ministério da Saúde (Brasil). Portaria $n^{\circ}$. 569, 570, 571, 572 /GM. Estabelece o Programa de 
Humanização do Pré-Natal e do Nascimento. Diário Oficial da República Federativa do Brasil, Poder Executivo. Brasília: Ministério da Saúde; 2000.

8. Carvalho CCM, Souza ASR, Moraes Filho OB. Selective episiotomy: advances based on evidence. FEMINA. [Internet]. 2010 [acesso em: 21 aug 2016];38(5):265-70. Disponível em: http://files.bvs.br/upload/S/0100-

7254/2010/v38n5/a008.pdf

9. Beckmann MM, Stock OM. Antenatal perineal massage for reducing perineal trauma. Review. Cochrane database syst. rev. (online). [Internet]. 2013 [acesso em: 10 nov 2014];30(4): CD005123. Disponível em:

http://www.cochrane.org/CD005123/PREG ante natal-perineal-massage-for-reducing-perineal-

\section{trauma}

10. Pimenta LF, Ressel LB, Stumm KE. The cultural construction of the birth process. Rev. pesqui. cuid. fundam. (Online). [Internet]. 2013[acesso em: 25 nov 2014];5(4):591-8. Disponível em: http://www.seer.unirio.br/index.php/cuidadofun damental/article/view/2344

11. Conselho Federal de Enfermagem. Decreto № 94.406/87. Regulamenta a Lei № 7.498/1986. Dispõe sobre o exercício da enfermagem e da outras providências. Brasil: COFEN; 1986.

12. Ministério da Saúde (Brasil). Secretaria de Ciência, Tecnologia e Insumos Estratégicos. Departamento de Ciência e Tecnologia. Agenda Nacional de Prioridades de Pesquisa em Saúde. Brasília: Ministério da Saúde; 2011.

13. Figueiredo GS, Santos TTR, Reis CSC, Mouta RJO, Progianti JM, Vargens OMC. Ocorrência de episiotomia em partos acompanhados por enfermeiros obstetras em ambiente hospitalar. Rev. enferm. UERJ, Rio de Janeiro. [Internet]. 2011 [acesso em: 21 aug 2016] abr/jun;19(2):181$85 . \quad$ Disponível em: http://www.facenf.uerj.br/v19n2/v19n2a02.pdf

14. Minayo MCS. O desafio do conhecimento: pesquisa qualitativa em saúde. 13 th ed. São Paulo: Hucitec; 2013.

15. Conselho Nacional de Saúde. Resolução № 466/2012. Dispõe sobre as diretrizes e as normas regulamentadoras de pesquisa envolvendo seres humanos. Brasília: Conselho Nacional de Saúde; 2012.

16. Ministério da Saúde (Brasil). Humanização do parto e do nascimento. Brasília: Ministério da Saúde; 2014.

17. Silva, ALS; Nascimento ER; Coelho EAC; Nunes IM. Educación durante el pre-natal, bajo la mirada de las mujeres embarazadas. Rev Cuba Enf 2014; 30(1) 79-89. http://www.revenfermeria.sld.cu/index.php/enf/ article/view/487/82

18. Frigo J, Cagol G, Zocche DA, Zanotelli SS, Rodrigues RM, Ascari RA. Episiotomia: (des)conhecimento sobre o procedimento sob a ótica da mulher. Braz. J. Surg. Clin. Res. [Internet]. 2014 [acesso em: 10 jan 2015];6(2):5-10. Disponível em: http://www.mastereditora.com.br/periodico/201 40403 2003162.pdf

19. Zanotelli SS, Ressel LB, Borges ZN. Cuidado no Climatério: um olhar interdisciplinar. Florianópolis: Editora Universitária. 2011:44-57.

20. Reis SP, Bielemann VLM, Meincke SMK, Carraro TE, Neves MD, Soares MC, et al. Sentimentos das puérperas durante o trabalho de parto. J. nurs. health. [Internet]. 2012 [acesso em: 28 nov 2014];2(2):490-501. Disponível em: http://www2.ufpel.edu.br/revistas/index.php/enf ermagemesaude/article/view/224/235

21. BAguiar JM, D'Oliveira AFPL. Violência institucional em maternidades públicas sob a ótica das usuárias. Interface - Comunic., Saude, Educ. [Internet]. 2011 [acesso em: 24 jan 2014];15(36):79-92. Disponível em: http://www.scielo.br/pdf/icse/v15n36/aop4010. pdf

22. Conselho Federal de Medicina. Resolução CFM № 1931/2009. Art 22/IV. Direitos humanos. Brasília: Código de Ética Médica; 2009. Disponível em: http://www.portalmedico.org.br/resolucoes/CFM 2009/1931 2009.htm

23. Cortes LF, Vieira LB, Landerdahl MC, Padoin SMM. Compreensão de gênero e suas manifestações no cotidiano de um serviço de saúde. Rev. RENE. [Internet]. 2010 [acesso em: 15 set 2014];11(4):143-53. Disponível em: http://www.revistarene.ufc.br/revista/index.php/ revista/article/view/440

Nota: Artigo original proveniente de Trabalho de Conclusão de Curso.

Received in: 24/09/2016

Final version resubmitted on: 24/03/2017

Approved in: 27/03/2017

\section{Mailing address:}

Kelen da Costa Pompeu

Maurício Sirotsky Sobrinho Avenue - 354

ZIP CODE: 97020-440 Santa Maria/RS Brasil.

Email: kperottoni@gmail.com 